\section{References}

Armstrong, M. L., and Megan, M. B. (1972). Circulation Research, 30, 675. Beaumont, J. L., et al. (1970). Bulletin of the World Health Organization, 43, 891 .

Carlson, L. A., and Bottiger, L. E. (1972). Lancet, 1, 865.

Carlson, L. A., and Kolmodin-Hedman, B. (1972). Acta Medica Scandinavica, 192, 29.

Christakis, G., et al. (1966). American fournal of Public Health, 56, 299.

Cramp, D. G., and Robertson, G. (1968). Analytical Biochemistry, 25, 246.

Dayton, S., et al. (1969). Circulation, 40, Suppl. No. 2.

Dewar, H. A. (1971). British Medical fournal, 4, 767.

Fredrickson, D. S., Levy, R. I., and Lees, R. S. (1967). New England Fournal of Medicine, 276, 34, 94, 148, 215, 273.

Goldstein, J. L., et al. (1973). Fournal of Clinical Investigation, 52, 1533.

Hatch, F. T., and Lees, R. S. (1968). Analytical Biochemistry, 6, 1

Jones, R. L., and Dobrilovic, L. (1970). Fournal of Laboratory and Clinical Medicine, 75, 953 .

Keys, A. (editor) (1970). Circulation, 41, Suppl. No. 1, p. 1.

Krikler, D. M., Lefevre, D., and Lewis, B. (1971). Lancet, 1, 934

Krikler, D. M., Lefevre, D., and Lew

Leren, P. (1970). Circulation, 42, 935.
Lewis, B. (1973). Fournal of Clinical Pathology, 26, Suppl. No. 5, p. 26.

Lewis, B., et al. (1974). Lancet, 1, 141.
Lloyd, J. K. (1973). Fournal of Clinical Pathology, 26, Suppl. No. 5, p. 53. Metropolitan Life Insurance Company (1959). Statistical Bulletin, 40, Feb., p. 1.

Miettinen, M., et al. (1972). Lancet, 2, 835.

Moore, R. B., Varco, R. L., and Buchwald, H. (1973). American fournal of Cardiology, 31, 148.

Morris, J. N. (1968). Lancet, 2, 693.

National Heart and Lung Institute (1971). Dietary Management of Hyperlipoproteinaemia. Bethesda, U.S. Department of Health, Education and Welfare.

Norum, K. R., Glomset, J. A., and Gjone, E. (1972). In Metabolic Basis of Inherited Disease, ed. J. B. Stanbury, J. B. Wyngaarden, and D. S. Fredrickson, 3rd edn., p. 531. New York, McGraw-Hill.

Oliver, M. F. (1971). British Medical fournal, 4, 775.

Stamler, J. (1967). Lectures on Preventive Cardiology. New York, Grune and Stratton.

Stamler, J., et al. (1968). Annals of the New York Academy of Sciences, 149,

Starzl, T. E., et al. (1973). Lancet, 2, 940.

Strisower, E. H., Adamson, G., and Strisower, B. (1968). American fournal of Medicine, 45, 488.

Wilson, D. E., and Lees, R. S. (1972). Fournal of Clinical Investigation, 51, 1051 .

\title{
Malabsorption in Overland Travellers to India
}

\author{
A. M. TOMKINS, W. P. T. JAMES, J. H. WALTERS, A. C. E. COLE
}

British Medical fournal, 1974, 3, 380-384

\section{Summary}

Thirty-four cases of malabsorption are described in young adults after brief periods of overland travel to India. Symptoms included diarrhoea, abdominal distension, and weight loss. Investigation revealed fat, xylose, and vitamin $\mathbf{B}_{12}$ malabsorption with marked morphological changes in the mucosa. Lower levels of serum folate and vitamin $\mathbf{B}_{12}$ were observed in those with protracted diarrhoea, but no anaemia developed. Malabsorption may persist for many months after return to the U.K. Most patients responded initially to antibiotics, but some subsequently relapsed. The reasons why these patients developed tropical sprue are discussed.

\section{Introduction}

Malabsorption occurring in expatriates living in the tropics for short periods of time has been described in Peace Corps volunteers in Pakistan (Lindenbaum et al., 1966) and in military personnel in Singapore (O'Brien and England, 1971) and Vietnam (Sheehy et al., 1965). Malabsorption may also occur occasionally after a variety of infective enteritis contracted outside the tropics (Montgomery et al., 1973).

In the last decade overland travel, particularly to the subcontinent of India, has become increasingly popular. We report clinical findings in 34 travellers who developed persistent malabsorption during their journey.

\footnotetext{
Clinical Nutrition and Metabolism Unit, London School of Hygiene and Tropical Medicine, London W.C.1

A. M. TOMKINS, M.B., M.R.C.P., Research Fellow

W. P. T. JAMES, M.D., M.R.C.P., Senior Lecturer (Present address: Dunn Nutritional Laboratory, Milton Road, Cambridge CH4 1XJ)

Hospital for Tropical Diseases, London NW1 2PE

J. H WALTERS, M.D., F.R.C.P., Consultant Physician

A. C. E. COLE, M.D., F.R.C.P., Consultant Physician
}

\section{Patients}

The 28 men and six women had a mean age of 25 (range 19-39 years). All were Caucasian but of different nationalities -23 Britons, five North Americans, four Australasians, and two South Africans. Patients were all seen initially as outpatients; only those who completed all the necessary investigations of malabsorption were included in the series.

They had had symptoms of diarrhoea for between one and nine months and evidence of malabsorption consistent with the definition of tropical sprue agreed by the Wellcome Trust Collaborative Studies (Mathan and Baker, 1971; Mollin and Booth, 1971; O'Brien and England, 1971). Patients were not included in this series if they were found to have gluten enteropathy, Crohn's disease, or other anatomical or immunological bowel disorders. Patients were also excluded if they had infection with Giardia lamblia, Strongyloides stercoralis, or Ascaris lumbricoides.

The 34 patients included in the series were all healthy and of normal weight before their overland journey. They nearly all undertook their journey as a holiday or as part of an attempt to change their way of life; only one man travelled for business reasons. Though the availability of marijuana was an undoubted attraction no patient was known to be addicted to alcohol or drugs taken by injection either before or after his journey. Very few travelled by one means of transport; most journeyed partly by foot, donkey, truck, bus, or train and often linked up with other groups of young wandering Caucasians. Most were on limited budgets and ate the same food and drank the same water as that taken by the indigenous population. Only rarely was this supplemented by the additional purchase of meat or fresh vegetables as both commodities were relatively expensive and of ten unobtainable.

The route most commonly taken and the main areas where the initial bout of severe diarrhoea occurred are shown in fig. 1. Diarrhoea most frequently started in Kabul and Katmandu, but these were probably the two most commonly visited towns and not necessarily those in which tropical sprue is particularly likely to develop. Two patients in the series developed their diarrhoea in north-west Africa. 
In most cases the illness started with an acute attack of diarrhoea and vomiting, accompanied occasionally by fever, with diarrhoea persisting after the initial episode. Several patients were admitted moribund to local hospitals for intravenous therapy. Of those who survived, most were discharged with persisting diarrhoea and pale bulky stools. Patients complained of abdominal distension with colicky pain and a weight loss of $5-20 \mathrm{~kg}$. Antibiotics were usually taken at some stage but often for two or three days only. An initial transient improvement in diarrhoea seemed to occur, but symptoms soon returned after stopping the antibiotics.

Examination usually showed a weak patient with marked muscular wasting. The abdomen was distended and there were increased bowel sounds. One anicteric patient had an enlarged liver palpable $4 \mathrm{~cm}$ below the costal margin associated with raised serum transaminase levels. There was no case of neuropathy, oedema, hair change, or skin exfoliation, but three patients had glossitis. below $5 \mathrm{~g} /$ day and this was presumed to have resulted from a deliberate avoidance of fat. Most patients, given the opportunity, were very selective in their choice of foods with a marked preference for fat-free meals and vegetarian or "health food" diets. After the fat balance the food intake of all patients was monitored to ensure that additional fat was taken with an intake of 90-110 g. This allowed mean daily faecal weight to be used as an index of progress and treatment. Stool output was unreliably estimated by both patient and clinician, and it could only be assessed accurately by a complete collection of stools in cellophane bags. The time and weight of the stool output was recorded so that daily faecal weights could be calculated.

Intestinal Biopsy.-Proximal jejunal biopsy was performed using the Watson or Quinton capsule. Specimens were examined under the dissecting microscope and appearances were recorded as "flat," "convoluted," "ridges," or "fingers" (Booth et al., 1962). The specimens were then embedded and

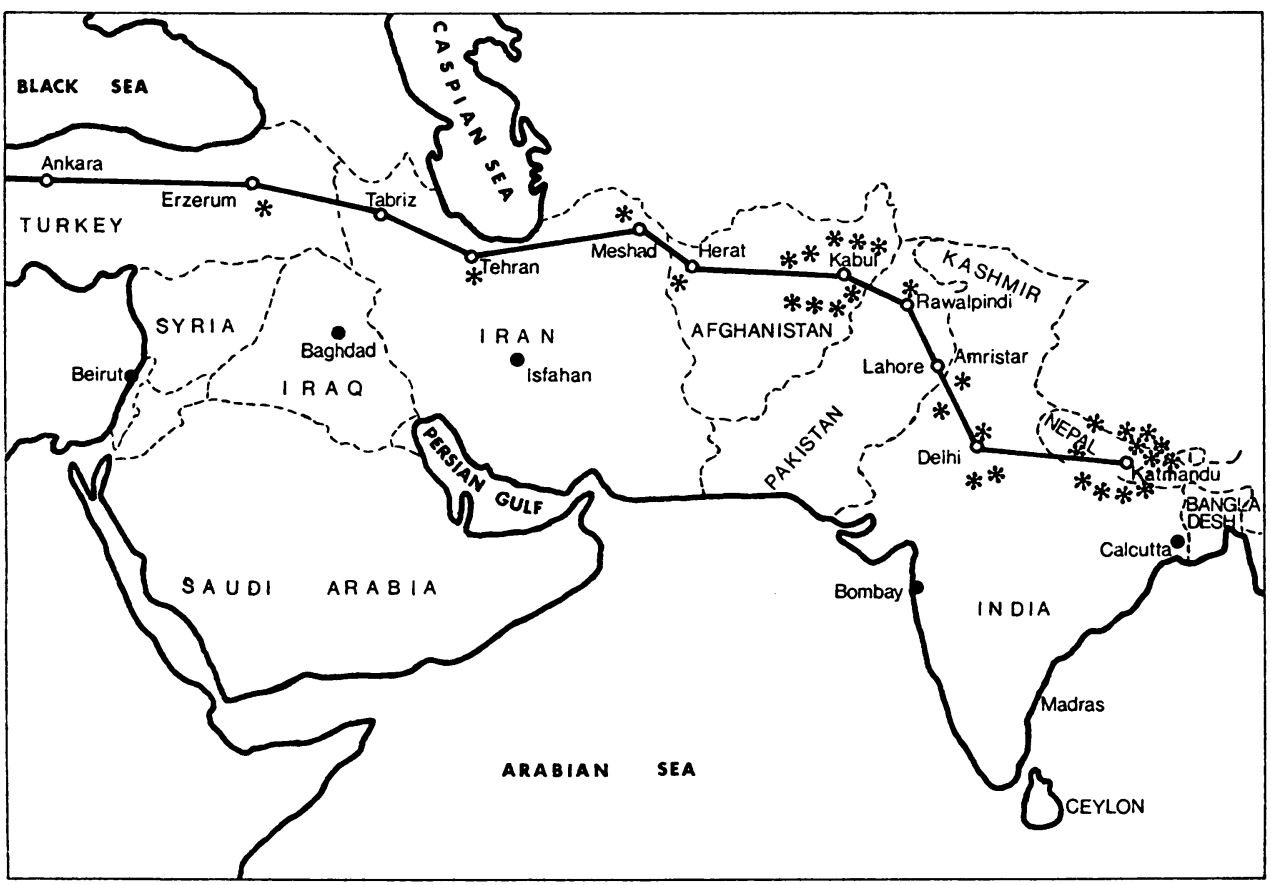

FIG. 1-Route taken by overland travellers. Asterisks indicate site of onset of diarrhoea.

\section{Methods}

Microbiology.-At least two stools and one specimen of jejunal aspirate taken at the time of biopsy were examined for ova, cysts, and parasites. Aerobic culture of stools were performed and a more detailed assessment of small intestinal bacteriology is in progress.

Intestinal Function.-The five-hour urinary excretion of xylose after a $25 \mathrm{-g}$ oral load was estimated by the spectrophotometric method of Roe and Rice (1948). Serum folate levels were measured with a Lactobaccillus casei assay and serum vitamin $\mathbf{B}_{12}$ by assay with Euglena gracilis. A Schilling test was performed with an oral dose of $1.0 \mu \mathrm{g}{ }^{58} \mathrm{Co}-\mathrm{B}_{12}$ together with hog intrinsic factor after a "flushing" parenteral dose of $1 \mathrm{mg}$ of nonradioactive vitamin $B_{12}$ given at the same time as the ${ }^{58} \mathrm{Co}-\mathrm{B}_{12}$. Faecal fat estimation were performed on a three-day collection by the method of Kamer (1958). Fat absorption was assessed with patients on a standardized fat intake of 97-105 $\mathrm{g}$ with a constant fibre content of about $10 \mathrm{~g}$. Carmine markers were used to delineate a three-day intake and the excretion of fat. Six patients who were investigated at the beginning of the series were maintained on a normal ward diet during fat absorption tests. Five of these proved to have faecal fat excretion sections made with particular care to achieve section in the perpendicular plane.

Treatment.-In the earlier part of the study patients received tetracycline $250 \mathrm{mg}$ every six hours for two weeks followed by sulphadimidine $0.5 \mathrm{~g}$ every six hours for two weeks. Most patients also received folic acid. Later in the study patients were treated with tetracycline $250 \mathrm{mg}$ sixhourly without supplementary folic acid.

\section{Results}

Mean haemoglobin was $14.5 \mathrm{~g} / 100 \mathrm{ml}$ (range 12.1-16.6), mean albumin was $4.4 \mathrm{~g} / 100 \mathrm{ml}$ (range 3.7-4.6). The mean "weight for height" index (Society of Actuaries, 1966) was in the range $80-84 \%$ of adult standard. Mean triceps skinfold was $7 \cdot 4 \mathrm{~mm}$ (range $3 \cdot 1-16 \cdot 8$ ), which was less than $60 \%$ of adult standard and reflected loss of body fat (Jelliffe, 1966).

Stool weights on admission were on average $360 \mathrm{~g} /$ day, but the mean weight varied from $180 \mathrm{~g} /$ day-2,005 g/day. The daily stool weight in a subject on a western diet should not exceed $200 \mathrm{~g}$. The results of tests of absorption are shown in table I. Only one patient had a normal xylose 
excretion. Of the 34 patients 29 had steatorrhoea and this figure might have been higher if all the patients had been on a constant fat intake. In fact all the patients who received a constant fat diet had steatorrhoea. A test of vitamin $\mathbf{B}_{12}$ absorption which included intrinsic factor in 12 patients showed that all except one had malabsorption, and the mean serum vitamin $\mathbf{B}_{12}$ levels when plotted against duration of diarrhoea showed a steady decline as symptoms became more prolonged. Serum folate levels showed a more rapid fall as the duration of symptoms increased (fig. 2). The patients with prolonged diarrhoea of eight or nine months duration were admitted after their arrival in the U.K. and had been eating a western diet for at least two to seven months before investigation.

TABLE I-Results of Tests of Absorption

\begin{tabular}{l|c|c}
\hline & & $\begin{array}{c}\text { Proportion with } \\
\text { Abnormal Result }\end{array}$ \\
\hline Faecal fat (g/day) & Mean and Range & $29 / 34$ \\
Xylose (g) & $15 \cdot 2(2 \cdot 2-40 \cdot 6)$ & $33 / 34$ \\
Vitamin B12 absorption (\% dose & $2 \cdot 2(0 \cdot 4-5 \cdot 0)$ & $11 / 12$ \\
excreted) & $2 \cdot 9(0-12 \cdot 0)$ & $0 / 11$ \\
14C-Glycocholate breath test & Negative &
\end{tabular}

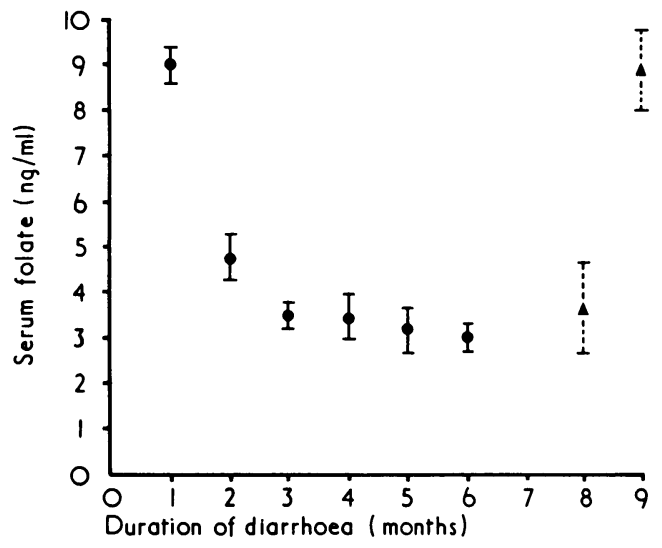

FIG. 2-Relation of serum folate levels to duration of diarrhoea. Dotted lines indicate those patients who had been in UK for more than two months before admission. been in UK for more than two months

The dissecting microscope appearances of jejunal biopsy specimens showed abnormalities in all cases, but no one had a flat mucosa. The biopsy appearances were related to duration of symptoms (table II) and suggested increasing severity of mucosal lesion as symptoms persisted. There were less severe changes in those with very prolonged symptoms, which occurred in patients who had been on a western diet for some time since their return. TABLE II-Relation of Appearances on Dissecting Microscopy to Duration of
Diarrhoea in Patients with Malabsorption. Results expressed as Numbers of Diarrhoea
Patients

\begin{tabular}{l|c|c|c}
\hline \multirow{2}{*}{ Microscope Appearances } & \multicolumn{2}{|c}{ Duration of Diarrhoea } & (Months) \\
\cline { 2 - 4 } & $1-3$ & $4-6$ & $7-9$ \\
\hline Leaves & 8 & 1 & 2 \\
Ridges & 4 & 5 & 5 \\
Convolutions & 0 & 8 & 1 \\
\hline
\end{tabular}

Light microscopy showed shortened villi with infiltrations of the lamina propria and epithelium by plasma cells and lymphocytes. Bacteriological studies were performed in six cases and culture of luminal fluid showed predominantly aerobic organisms with counts of $10^{4}-10^{3}$ organisms $/ \mathrm{ml}$. More detailed accounts of the microflora and its relation to structure and function will be published elsewhere.

Barium follow-through examination showed a normal small intestine pattern in seven patients, a coarse mucosal pattern in the jejunum in 16 patients, and a coarse mucosa together with dilation of jejunum and occasionally ileum in 11 .

\section{RESPONSE TO TREATMENT}

Each of the six patients on tetracycline therapy alone showed improvement in stool and body weight (fig. 3), but a clear response was not necessarily evident until after four weeks of therapy. Most patients noticed some improvement in diarrhoea about three to four days after starting treatment, and all noticed an improvement in wellbeing and appetite at the end of the first week of treatment.
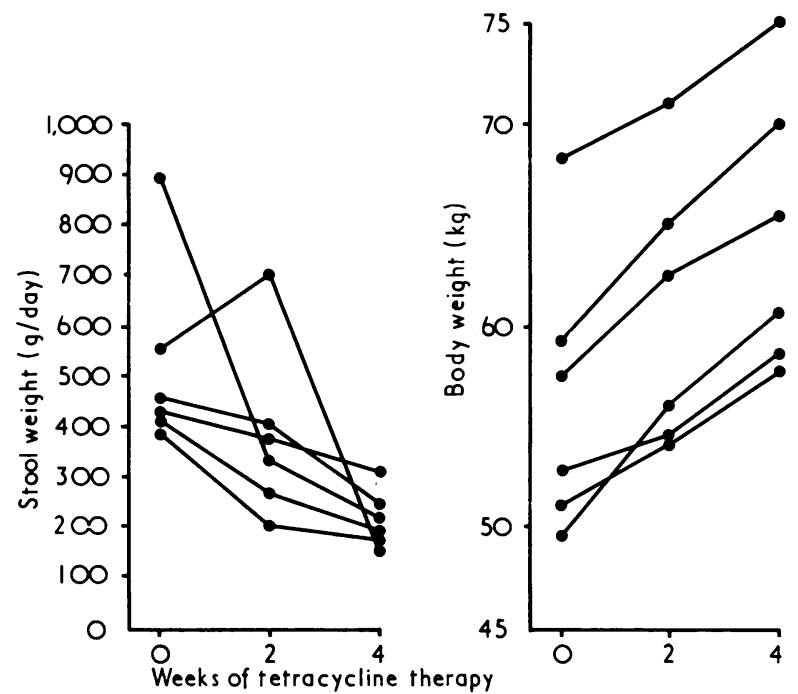

FIG. 3-Response of stool and body weight to tetracycline theraj)y.

\section{Discussion}

The definition of tropical sprue has varied in the past and this problem has hindered an understanding of its pathogenesis. It is well recognized that there is a high incidence of abnormalities in small intestinal morphology and function in apparently normal subjects resident in many areas of the Third World (Klipstein and Baker, 1970). These abnormalities also occur in expatriates entering a tropical area. Intestinal changes are more common in those who live in close contact with the local environment-for example, American Peace Corps volunteers-than those who live more sheltered lives (Lindenbaum et al., 1966). Malabsorption of xylose, vitamin $B_{12}$, and occasionally fat may develop in association with mild changes in mucosal morphology. The mucosa of ten shows changes of leaf formation only when viewed with the dissecting microscope, and lymphocytic infiltration of the lamina propria is often the only histological abnormality (Lindenbaum, 1973). Furthermore, the structure and function of the small intestine often improves when both expatriates and natives move to live in more developed countries (Sheehy et al., 1965). This mild abnormality, presumably of environmental origin, has been termed "subclinical enteropathy" to indicate that it is usually asymptomatic.

Cases of enteropathy with severe malabsorption are classified as "tropical sprue" though they may only represent the 
other end of the spectrum of intestinal damage discussed above. Some of these patients also have megaloblastic anaemia and hypoproteinaemia (Klipstein et al., 1968), which further complicates their differentiation from patients with primary protein malnutrition (Mayoral et al., 1968). Between the two extremes of intestinal change there are many cases which are arbitrarily classified on clinical grounds as either subclinical enteropathy or tropical sprue. Though epidemiological and clinical differences between the two have been noted-for example, the adult age distribution and the typically acute onset and severity of tropical sprue (Baker and Mathan, 1970)-the mucosal changes appear no different in sprue and subclinical enteropathy, and the diagnosis of sprue still seems to be reserved for those patients with symptomatic malabsorption. Klipstein and Baker (1970) have suggested that the diagnosis of tropical sprue should depend on showing malabsorption of two unrelated substances, but this would then include many patients with subclinical enteropathy (Lindenbaum, 1973). It should also be noted that these diagnostic criteria for sprue do not distinguish malabsorption of xylose and vitamin $B_{12}$ of gut bacterial origin (Goldstein et al., 1970; Gianella et al., 1972) from malabsorption arising from mucosal damage, and both mechanisms contribute to the malabsorption in acute cases of tropical malabsorption (Gorbach et al., 1970).

The pathogenesis of tropical sprue is unknown but environmental factors are thought to be important. The rapidity of onset (Rowe et al., 1970) and case distribution in epidemiological studies (Mathan and Baker, 1971) suggest an infective agent. Bacterial infection with enterotoxin producing Escherichia Coli has been shown in some acute cases (Gorbach, et al. 1970), and a variety of bacterial species have been isolated in great numbers from the few patients studied with chronic tropical sprue (Mollin and Booth, 1971). Agents in drinking water, such as algae (Bernstein et al., 1973), may be a factor in our patients as they were constantly exposed to the possibility of infection from locally produced food or water. Tropical sprue is usually thought to occur only in the subcontinent of India, South East Asia, some countries of South America and some of the West Indian islands. It is said not to occur in Africa (Manson-Bahr, 1953) though Falaiye (1970) has described cases of malabsorption which responded to tetracycline in Nigeria. Despite the many patients who have travelled overland in Africa and subsequently presented with diarrhoea at our hospital only three in five vears have had tropical sprue.

When removed from the tropical environment our patients often noticed an improvement in their diarrhoea. Improvement often began on their homeward journey through Europe and continued on their return to the U.K. Some travellers suffered from incapacitating diarrhoea in India but improved within a few days of arriving by air in the U.K. This suggests that there was either a persistent agent maintaining the diarrhoea in the tropical environment or that the change in dietary intake on return to U.K. was relevant.

Folate deficiency is frequently associated with tropical sprue and the development of folic acid deficiency during pregnancy may precipitate an attack (O'Brien and England, 1971). Our patients ate infrequently because of lack of funds, and they usually took locally prepared continuously reheated food from village stalls. Such methods of food preparation are known seriously to deplete the diet of folate (Herbert, 1968) and may explain the higher incidence of malabsorption in vegetarian than in meat-eating Indian soldiers consuming cooked rations during an epidemic of tropical sprue (Walters, 1947). Once tropical sprue is established there may be further folate depletion as dietary folate is consumed by bacteria (Hoffbrand et al., 1971), fails to be hydrolysed from the polyglutamate form (Klipstein, 1969), and is excessively excreted in the faeces (Baker, 1968). The serum folate levels in our patients decreased as symptoms persisted, but no patient developed anaemia. This resistance to anaemia may well have reflected the good nutritional status of these patients before their illness as tropical sprue is more often associated with megaloblastic anaemia in areas with a higher incidence of malnutrition (Klipstein, 1969).

Many of our patients experienced a delay in diagnosis. Even patients with severe diarrhoea who flew to the U.K. because they were too ill to return overland were often treated in hospitals or at home with symptomatic treatment alone-for example, codeine or diphenoxylate hydrochloride -without adequate assessment of malabsorption. Investigations were often limited to culture of the stool for dysenteric organisms and an examination for ova or parasites. Parasitological investigation is certainly important since many patients prove to have $G$. lamblia in their stools. Some cases, however, may only be diagnosed by showing the trophozoites or cysts in jejunal fluid or in a biopsy specimen (Ament and Rubin, 1972). Since sprue remains a diagnosis by exclusion in patients with malabsorption a thorough examination is required. Some patients have isolated lactose intolerance while others prove to have non-tropical causes of malabsorption. During our investigations two patients were seen who failed to improve on antibiotics. Both patients (not included in the present study) showed clinical and histological improvement on gluten withdrawal. A further patient was found to have jejunal diverticuloses with an abnormal ${ }^{14} \mathrm{C}$-glycocholic acid breath test result.

Treatment of tropical sprue is usually by replacement therapy with vitamins where anaemia occurs and by attempting to affect the underlying mucosal disorder. Spontaneous regression usually occurs only in milder cases (O'Brien and England, 1971). Combinations of antibiotics have been used (Mollin and Booth, 1971), but tetracycline alone may produce rapid improvement in malabsorption (French et al., 1956), and our cases treated with a four-week course of oral tetracycline showed uniform improvement. Indeed a failure to respond after four weeks lead us to suspect another diagnosis. Full follow-up is necessary as some patients with chronic tropical sprue seem to relapse despite initial therapy (Mollin and Booth, 1971), and four of our 13 patients in whom adequate follow up was possible relapsed despite remaining in the U.K. Continuing symptoms of intermittent abdominal distension and some looseness of stool may relate to the associated lactose intolerance (Sheehy and Anderson, 1963) with only a very slow recovery in lactase activity.

Tropical sprue remains a puzzling disease with considerable morbidity and some mortality on an international scale. Overland travel to the tropics is becoming increasingly popular, and many young people return with diarrhoea and malabsorption. A full assessment of each patient and a better understanding of the cause of this syndrome is needed.

We thank the nursing staff of Manson ward and Miss Rose of the dietetic department for valuable help with the patients. None of this work would have been possible without the help of our metabolic nurse, Mrs. Ottaway. We acknowledge the advice and encouragement of Professor J. C. Waterlow and financial assistance from Ciba-Geigy Ltd.

\section{References}

Ament, M. E., and Rubin, C. E. (1972). Gastroenterology, 62, 216

Baker, S. J. (1968). Vitamins and Hormones, 26, 537.

Baker, S. J., and Mathan, V. I. (1970). Annals of Tropical Medicine and Parasitology, 64, 453.

Bernsteinitology, Gastroentogy, 64, 697

Booth, C. C., et al. (1962). Intestinal Biopsy, Ciba Foundation Study Group No. 14. London, Churchill.

Falaiye, J. (1970). Fournal of Tropical Medicine and Hygiene, 73, 119.

Falaiye, J. (1970). Fournal of Tropical Medicine and Hygiene, 73, 119. Medicine, 25, 333.

Gorbach, S. L., et al. (1970). American fournal of Clinical Nutrition, 23, 1545.

Gianella, R. A., Broitman, S. A., and Zamcheck, N. (1972). Gastroenterology, $62,255$.

Goldstein, F., et al. (1970). Gastroenterology, 59, 380.

Herbert, V. (1968). Vitamins and Hormones, 26, 525. 
Hoffbrand, A. V., et al. (1971). Gut, 12, 27.

Jelliffe, O. B. (editor) (1966). Assessment of the Nutritional Status of the Community. Geneva, World Health Organization

Kamer, J. H. Van der. (1958). In Standard Methods of Clinical Chemistry, ed. D. Seligson, Vol. 2, p. 34. New York, Academic Press.

Klipstein, F. A., (1969). Blood, 34, 191.

Klipstein, F. A., and Baker, S. J. (1970). Gastroenterology, 58, 717.

Klipstein, F. A., et al. (1968). American fournal of Clinical Nutrition, 21, 1042 .

Lindenbaum, J. (1973). Gastroenterology, 64, 637

Lindenbaum, J., Kent, T. H., and Sprinz, H. (1966). Annals of Internal Medicine, 65, 1201 .

Manson-Bahr, P. H. (1965). Lancet, 2, 839.

Mathan, V. I., and Baker, S. J. (1971). Tropical Sprue and Megaloblastic Anaemia, London, Churchill.
Mayoral, L. G., et al. (1968). American fournal of Clincial Nutrition, 21, 1053. Mollin, D. L., and Booth C. C. (1971). Tropical Sprue and Megaloblastic Anaemia. London, Churchill.

Montgomery, R. D., et al. (1973). British Medical fournal, 2, 265.

O'Bien, W., and England, N. W. J. (1971). Tropical Sprue and Megaloblastic Anaemia. London Churchill.

Roe, J. H., and Rice E. W. (1948). Fournal of Biological Chemistry, 173, 507. Rowe, B., Taylor, J., and Bettleheim, K. A. (1970). Lancet, 1, 1.

Sheehy, T. W., and Anderson, P. R. (1963). Lancet, 2, 1

Sheehy, T. W., et al. (1965). Fournal of the American Medical Association 194, 1069 .

Society of Actuaries. (1966). In Assessment of the Nutritional Status of the Community, ed. D. B. Jelliffe, p. 239. Geneva, World Health Organiza-

Walters, J. H. (1947). Lancet, 1, 861.

\title{
Blood Glucose Measurement with Dextrostix and New Reflectance Meter
}

\author{
BENGT SCHERSTEN, CLAUS KUHL， ANDERS HOLLENDER， ROLF EKMAN
}

British Medical fournal, 1974, 3, 384-387

\begin{abstract}
Summary
A new instrument, Eyetone, has been produced for use with a Dextrostix reagent strip for estimating blood sugar levels. It differs from the Dextrostix Reflectance Meter in having only one meter scale, a two-point calibration, and a range of measurement limited to $10-400$ $\mathrm{mg} / \mathbf{1 0 0} \mathrm{ml}$. Results with the manufacturers' original calibration were unsatisfactory, but when recalibrated the performance of the instrument gave a regression equation line close to the ideal. The three Eyetone instruments tested were comparable in their accuracy and functional stability. Packed cell volumes in the blood samples in the range of $30-50 \%$ had a negligible effect on the results. The Dextrostix-Eyetone method represents a quick and reliable alternative to conventional laboratory methods for blood sugar estimation. It is especially useful for patients outside hospital.
\end{abstract}

\section{Introduction}

The introduction in 1970 of the Dextrostix Reflectance Meter, which recorded electronically the blood glucose concentration equivalent of a colour on a Dextrostix reagent strip, was a valuable advance in the technology of blood sugar measurement. It obviated observer variations inevitable in the evaluation of colour (Cohen et al., 1964; Rennie et al., 1964; Scherstén, 1965) and it enabled blood sugar levels to be

\footnotetext{
Community Health Research Centre, Dalby, and Department of Internal Medicine, University Hospital of Lund, Sweden

BENGT SCHERSTÉN, M.D., Associate Professor of Medicine

Department of Internal Medicine, Bispebjerg Hospital, University of Copenhagen, Denmark

CLAUS KUHL, M.D., Research Fellow

Department of Clinical Chemistry, County Central Hospital, Boras, ANDERS HOLLENDER, M.D., Physician-in-Chief Department of Clinical Chemistry, University Hospital of Lund,
Sweden

ROLF EKMAN, M.D., Senior Registrar
}

measured accurately and rapidly without resort to laboratory assistance. Nevertheless, the instrument, though reliable in the middle range of blood glucose levels most commonly seen when treating diabetics (Jarrett et al., 1970; Joffe and Seftel, 1971; Scherstén, 1971; Forman et al., 1972; Percy-Robb et al., 1972; Kühl, 1973), has been criticized for being unreliable with very low levels and those above $200 \mathrm{mg} / 100 \mathrm{ml}$ (Junker and Ditzel, 1972; Kühl, 1973). In 1973 a new instrument, Eyetone, was introduced. This has a single meter scale for whole blood glucose levels in the range of $10-400 \mathrm{mg} / 100 \mathrm{ml}$; has two calibration strips, which allows for two-point calibration; and is mainsoperated. This paper reports on a multicentre study of the Dextrostix-Eyetone method of blood sugar estimation.

\section{Materials and Methods}

The directions in the operating manual for handling the Dextrostix strip and the Eyetone instrument were followed precisely. The recommended calibration points of 50 and $400 \mathrm{mg} / 100 \mathrm{ml}$ were later changed by the manufacturer to 40 and $300 \mathrm{mg} /$ $100 \mathrm{ml}$. A special study of standardization was therefore made at one centre.

Samples of venous blood were taken from both non-diabetics and diabetics and an anticoagulant (heparin or edetic acid) was added. Hypoglycaemic and hyperglycaemic specimens were also prepared-the former by allowing spontaneous glucolysis to occur in blood standing in a stoppered container at room temperature for several hours, and the latter by adding pure dextrose or a concentrated aqueous glucose solution.

The findings with the Dextrostix-Eyetone method were compared with those with the following three reference methods. Centre 1 (Community Health Centre, Dalby, and University Hospital of Lund) used the glucose oxidase method of Marks (1959) as modified by Brandt et al. (1964) together with a Vitatron UC 200. The mean day-to-day coefficient of variation for this method during two years was $3 \cdot 2 \pm$ S.D. $0.8 \%$ with a $95 \%$ confidence limit of $1 \cdot 5-5 \cdot 0 \%$. Centre 2 (University Hospital of Copenhagen) used the hexokinase method of Widdowson and Penton (1972) together with an AutoAnalyzer II. The day-to-day coefficient of variation during one month was $3 \cdot 4 \%$. Centre 3 (County Central Hospital, Borås) used the o-toluidine method of Hultman $(1957,1959)$ together with an AutoAnalyzer I. The day-to-day coefficient of variation during seven months was $3.6 \%$.

Comparison of these three reference methods showed a high 